\title{
EDUCAÇÃO ESPECIAL E INCLUSÃO: DIÁLOGOS SOBRE PESQUISA, POLÍTICAS E PRÁTICAS
}

\author{
EDUCACIÓN E INCLUSIÓN ESPECIAL: DIÁLOGOS SOBRE INVESTIGACIÓN, \\ POLÍTICAS Y PRÁCTICAS
}

\author{
SPECIAL EDUCATION AND INCLUSION: DIALOGUES ON RESEARCH, POLICIES \\ AND PRACTICES
}

\author{
Leonor Paniago ROCHA ${ }^{1}$ \\ Marlene Barbosa de Freitas REIS ${ }^{2}$ \\ Vanderlei Balbino da COSTA ${ }^{3}$
}

RESUMO: Investigação em educação; pesquisa narrativa em educação especial; inclusão escolar de pessoas com deficiência; dificuldades de aprendizagens específicas; práticas educativas inclusivas; formação continuada do professor para a identificação de superdotação; inclusão e diferença; medicalização, escala de avaliação de pessoas com deficiência intelectual; aplicabilidade das políticas públicas educacionais inclusivas; contribuições dos casos de ensino na educação inclusiva.

PALAVRAS-CHAVE: Educação especial. Inclusão. Pesquisa em educação. Dificuldades de aprendizagens específicas.

RESUMEN: Investigación educativa; investigación narrativa en educación especial; inclusión escolar de personas con discapacidad; dificultades específicas de aprendizaje; prácticas educativas inclusivas; formación continua del profesorado para identificar la superdotación; inclusión y diferencia; medicalización, escala de calificación para personas con discapacidad intelectual; aplicabilidad de políticas públicas educativas inclusivas; aportes de casos docentes en educación inclusiva.

\footnotetext{
${ }^{1}$ Universidade Federal de Jataí (UFJ), Jataí - GO - Brasil. Professora titular. Doutora em Educação - (PUCGO). Atualmente realiza pós-doutoramento no Programa de Pós-graduação interdisciplinar em Educação, Linguagem e Tecnologias da Universidade Estadual de Goiás (PPG-IELT). Membro do grupo de pesquisa; Formação de professores e saberes pedagógicos; cadastrado no Diretório dos Grupos de Pesquisa no Brasil, CNPq realizando pesquisa nas áreas da educação, diversidade, políticas públicas, deficiência e inclusão escolar. ORCID: https://orcid.org/0000-0003-1076-703X. E-mail: leonorpaniago.ufg@ hotmail.com

${ }^{2}$ Universidade Estadual de Goiás (UEG), Anápolis - GO - Brasil. Professora titular. Docente do quadro permanente do Programa de Pós-graduação interdisciplinar em Educação, Linguagem e Tecnologias (PPGIELT). Pós doutora em Gestão da Informação e Conhecimento pela Universidade do Porto, Portugal (2015). Professora do Curso de Pedagogia (UEG/Inhumas). Membro do grupo de pesquisa; Formação de professores e saberes pedagógicos - Diretório dos Grupos de Pesquisa no Brasil - CNPq. ORCID: https://orcid.org/0000-00022213-7281. E-mail: marlenebfreis@ hotmail.com

${ }^{3}$ Universidade Federal de Jataí (UFJ), Jataí - GO - Brasil. Professor titular. Docente do Programa de Pósgraduação em Educação (PPGE). Doutor em Educação Especial pela Universidade Federal de São Carlos (2012). Desenvolve os projetos de pesquisa: Políticas de Ação Afirmativa na Universidade: Possibilidades de Inclusão no Ensino Superior; Projeto de Acessibilidade (2015/2018); A Formação Docente nas Escolas Públicas de Jataí- GO (2013/2018). ORCID: https://orcid.org/0000-0002-1330-747X. E-mail:
} vanderleibalbino@gmail.com 
PALABRAS CLAVE: Educación especial Inclusión. Investigación educativa. Dificultades específicas de aprendizaje.

ABSTRACT: Investigation on education; narrative research on special education; school inclusion of people with disabilities; specific learning difficulties; educative inclusive practices; continuing teacher education for identifying Intellectual giftedness; inclusion and difference; medicalization; rating scale for people with intellectual disabilities; applicability of inclusive educational public policies; contributions of teaching cases in inclusive education.

KEYWORDS: Special education. Inclusion. Education research. Specific learning difficulties.

\section{Considerações iniciais}

Em tempos de discursos que afirmam que "As universidades devem ficar reservadas para uma elite intelectual" e que decretos surgem extinguindo secretarias como a Secretaria de Educação Continuada Alfabetização, Diversidade e Inclusão, SECADI e conselhos como o Conselho Nacional dos Direitos da Pessoa com Deficiência, CONADE, se faz necessário dar voz a pesquisadores de diversas regiões do país e deixar que seus diálogos tragam à baila o que suas pesquisas têm revelado sobre a inclusão escolar das pessoas com deficiência, em seus mais diferentes âmbitos. Também é preciso conhecer o que pesquisadores de outros países têm revelado sobre o tema. Esse é um modo simples de dizer às pessoas com deficiência e aos gestores públicos: estamos aqui!

Nesse sentido, o dossiê Educação Especial e Inclusão: diálogos sobre pesquisa, políticas e práticas, objetiva oferecer ao leitor oportunidade de refletir sobre esses aspectos que envolvem a inclusão escolar das pessoas com deficiência. Compreende-se que esses formam a tríade necessária para oferecer harmonia a educação especial/inclusiva, em qualquer território.

No Brasil e em muitos outros países, apesar da ampliação das políticas de inclusão escolar, da produção de pesquisas e discussões envolvendo as práticas de escolarização de alunos com necessidades educacionais especiais, o cotidiano de muitas escolas ainda mantêm concepções e currículos tradicionais e segregativos, não garantindo a aprendizagem de todos os alunos, em especial, os com alguma deficiência.

Nesse sentido, esse dossiê se insere no contexto das discussões sobre a inclusão das pessoas com deficiência na educação, partindo da importância de se pensar o modo de realizar 
pesquisa com esse grupo e de se pensar a prática pedagógica desenvolvida para promover seu desenvolvimento e sua inclusão, bem como as políticas educacionais destinadas a este.

Assim, a proposta deste texto, que abre esse dossiê, mais do que apresentar cada artigo que o compõe, pretende trazer uma discussão acerca da temática da inclusão da pessoa com deficiência e levar o leitor a compreender por que optamos por essa temática.

De início queremos afirmar que, optamos, nesse dossiê, por tratar dos processos de inclusão, porque todos concordamos que "Qualquer discriminação é imoral e lutar contra ela é um dever por mais que se reconheça a força dos condicionamentos a enfrentar. A boniteza de ser gente se acha, entre outras coisas, nessa possibilidade e nesse dever de brigar" (FREIRE, 1996, p. 67).

Foi essa boniteza de ser gente que impulsionou cada um dos autores que estão aqui nesse dossiê. Cada um, imbuído do mesmo propósito, elaborou seu texto e mostrou que escrever também é uma forma de se brigar por uma causa, ou um grupo.

Foi o desejo de que haja verdadeiramente inclusão de todos, em todos os espaços da sociedade, que nos moveram até aqui. De diferentes modos, cada autor dos textos que se encontram nesse dossiê sonha e luta por uma escola includente e uma sociedade onde a justiça se faça presente no cotidiano de todos.

Assim, os artigos desse dossiê tratam de três grandes temas referente a educação das pessoas com deficiência: as metodologias de pesquisa com sujeitos com deficiência, as políticas destinadas a esse grupo e as práticas desenvolvidas para atuar com os alunos com deficiência.

A dúvida, sobre como coletar dados com sujeitos com deficiência é algo sempre presente na elaboração dos projetos de pesquisa de pesquisadores que têm esses sujeitos como participantes de seus estudos, afinal, a "metodologia é o caminho do pensamento e a prática exercida na abordagem da realidade (MINAYO, 2000, p. 16)." Como abordar a realidade de um sujeito minorizado pela sociedade, por tantas vezes esquecido pelas políticas públicas e estranhado por tantos? Como compreender o universo da deficiência estando em um estado de "normalidade", sendo a ação de compreender, a base e o sentido da pesquisa qualitativa? São tantos: como, que sentimos a necessidade desse dossiê tratar a temática.

Em “A pesquisa narrativa em educação especial”, Leonor Paniago e Marlene Reis apresentam as contribuições da pesquisa narrativa para a compreensão dos processos de inclusão de alunos com deficiência, tratando a pesquisa narrativa como metodologia importante para se revisitar o passado, promover autoformação e formação. Apresentam as especificidades das narrativas no contexto das pesquisas na área da educação e defendem que 
a estória de vida, de um sujeito com deficiência, é particularmente proveitosa para a Educação Especial, ou outros campos de conhecimento que lidam com grupos excluídos, pois favorece a reflexão em relação às situações vividas pelo sujeito, as influências da exclusão no âmbito pessoal, social, econômico, político e educacional, bem como é capaz de apontar a necessidade de mudanças nas políticas, na cultura e na sociedade.

Utilizando de autores como Thesing e Costas (2017), elas defendem a pesquisa como uma atividade voltada à compreensão do mundo, ao desejo de desvendar o que está oculto. Uma atividade que está relacionada ao indagar, ao questionar o que está dado, ao que parece natural, colocando o pesquisador como um estranhador e questionador, inconformado ao posto como correto, como ordem. Fortalecem a ideia, de tantos outros autores, de que no contexto da vida e dos cursos de formação de professores, as experiências são conteúdos que merecem ser conhecidos, porque trazem reflexões que acarretam auto formação e possibilidades de formação. Logo, coletá-las e/ou narrá-las por meio de narrativas, representa uma grande oportunidade de crescimento, tanto para quem narra, quanto para quem escuta.

\section{Em "Fenomenologia: um caminho para compreensão de processos inclusivos",} Edileine Machado e Fátima Denari, com objetivos semelhantes as autoras do texto anterior, apresentam um estudo de caso que evidenciou as contribuições do método fenomenológico para a compreensão dos processos inclusivos. Elas defendem esse método como um caminho possível para a formação do sujeito includente, visto que este possibilita a compreensão de processos também includentes, mais especificamente, o ponto de partida: conhecimento gnosiológico, ontológico e psicológico das pessoas envolvidas.

Em "Formação continuada de professores para educação inclusiva: uma experiência com casos de ensino", Isa Mara, Viviane Duek, Mizukami, Lúcia de Araújo apresentam ao leitor um caso de ensino, proporcionando a este a compreensão do potencial dos casos de ensino para a aprendizagem e o desenvolvimento profissional docente no contexto da educação que pretende incluir. Afirmam, que os casos de ensino contribuem para ampliação dos conhecimentos do docente sobre a inclusão de alunos com deficiência, gerando questionamentos acerca da prática pedagógica e possível redimensionamento. Elas afirmam que os casos de ensino potencializam a aprendizagem e a reflexão docente e sugerem a sua adequação, como estratégia de formação de professores, com vistas ao ensino que garanta a inclusão.

Discutir inclusão significa tratar de políticas públicas, ou, da falta delas. Assim, o segundo tema levantado por esse dossiê são as políticas. Três dos artigos aqui apresentados, 
ou tratam especificamente das políticas públicas para a inclusão das pessoas com deficiência, ou as apontam como interveniente neste processo.

No cenário mundial, é profícuo acentuar que processos de segregação, exclusão e marginalização se fizeram presentes em relação às pessoas com deficiência em todos os níveis. Isso se evidencia nos escritos de Mises (1977, p. 14), ao assinalar que:

Nós matamos os cães danados e touros ferozes, degolamos ovelhas doentes, asfixiamos recém-nascidos mal constituídos; mesmo as crianças se forem débeis ou anormais, nós as afogamos, não se trata de ódio, mas da razão que nos convida a separar das partes sãs aquelas que podem corrompê-las.

Lembramos tais ações para lembrar que foi no descortinar do século XVIII, em plena era das ideias iluministas, pautados nos ideais de liberdade, igualdade e fraternidade, que esses seres indesejáveis pela sociedade passaram a ser objeto de estudo da medicina, que os viam como doentes e necessitados de tratamento. Assinalar assim, que nascem aí, as primeiras ações políticas mundo afora, claro, não com a intenção ainda de promover à inclusão desses novos sujeitos, mas sim, abrigá-los em lares cristãos, instituições filantrópicas, asilos, hospitais, dentre outras instituições que se prestavam a esse fim.

O marco histórico da educação especial no Brasil se inicia no século XIX, em especial, quando o governo imperial em 1850, cria as primeiras instituições para abrigar as pessoas com deficiência. Foram criados neste período o Instituto Imperial dos Meninos Cegos em 1854 e o Instituto Imperial dos Surdos-mudos em 1857.

É de fundamental importância ressaltar que esses dois institutos foram criados na cidade do Rio de Janeiro e, posteriormente, passaram a ser chamados de Instituto Benjamin Constant (IBC) e Instituto Nacional de Educação de Surdos (INES). Só para exemplificar, no ano de 1872, havia no Brasil aproximadamente 15.848 deficientes visuais e 11.595 deficientes auditivos, porém, apenas 35 deficientes visuais e 17 deficientes auditivos eram atendidos por esses dois institutos. Os dados revelam que em pleno século XIX, as políticas públicas voltadas à inclusão das pessoas com deficiência eram insignificantes para atender o grande número de sujeitos que necessitavam desse serviço. É necessário assinalar que estamos falando nesse período apenas sobre duas deficiências, a visual e a auditiva, as demais ainda se encontravam invisibilizadas pelo governo.

No século XX, o mundo é marcado por diversas transformações políticas, econômicas, sociais, culturais e religiosas. Neste século, tivemos duas grandes guerras mundiais que, juntas, dizimaram milhões de pessoas no planeta. Os conflitos armados contribuíram para que se elevasse o número de pessoas mutiladas. Esse crescimento por sua vez contribuiu para que 
governantes dos diversos países, assolados pela guerra, passassem a pensar em políticas públicas de inserção dessas pessoas na sociedade.

No século XX, presenciamos, em relação a educação, diversos movimentos internacionais, como a Declaração de Jomtien - Tailândia (UNESCO, 1990); a Declaração de Salamanca - Espanha (UNESCO, 1994), dentre outros que passaram a dirimir normas para a proclamação da inclusão de todas as pessoas nas escolas comuns. Esses movimentos que se espraiaram ao redor do planeta não foram suficientes para garantir os processos inclusivos dos minorizados que ainda estão às margens da sociedade, como os indígenas, negros, quilombolas e pessoas com deficiência.

No sistema educacional brasileiro, presenciamos a criação da Lei de Diretrizes e Bases da Educação Nacional (LDBEN) Lei No 9.394/96, colocando, pela primeira vez, a educação especial em um documento desse porte.

Atualmente, em maio de 2015, ocorreu, na cidade de Incheon, Coreia do Sul, o Fórum Mundial de Educação, organizado pela UNESCO. Neste evento, que contou com a participação de mais de 100 Ministros da Educação e vários representantes da sociedade civil, realizou-se um balanço das metas de Educação para todos, relativas ao período 2000-2015, o debate e a sistematização dos princípios e diretrizes que para os próximos 15 anos (2016 a 2030).

Nesse fórum ficou definido que a educação é um direito humano fundamental e deve ser oferecida de forma equitativa, gratuita, inclusiva, devendo ser de qualidade e obrigatória. Deve ter como objetivo o pleno desenvolvimento da personalidade humana, a compreensão mútua, a tolerância, a amizade e a paz. A declaração, oriunda desse fórum, afirma ser a educação um bem público, do qual o Estado é o provedor desse direito (UNESCO, 2015).

Mesmo com todas essas Leis, decretos, resoluções e declarações presentes no cenário brasileiro, os direitos das pessoas com deficiência ainda são muito desrespeitados, como podemos ver no artigo "Os recursos de acessibilidade e tecnologia assistiva na sala de recursos multifuncionais nas escolas municipais de Manaus/AM", dos colegas Maria Almerinda, Christiane, Danilo e Geyse, presente nesse dossiê.

Esse artigo denuncia que o acesso às tecnologias assistivas, bem como o direito a acessibilidade não vem sendo garantidos em todos os espaços educativos, pelo poder público.

No que concerne às garantias da LBI $N^{\circ} 13.146$, ressaltamos que esta contempla também em seu inciso XIII, acesso à educação superior, à educação profissional e tecnológica em igualdade de oportunidades e condições com as demais pessoas. Essa premissa é partilhada por Maria Almerinda, Christiane, Danilo e Geyse, ao acentuar que embora 
existentes, os recursos tecnológicos acessíveis nas escolas da rede básica, ainda não estão disponíveis no ensino superior para todas as pessoas com deficiência.

Com a publicação da LBI-13.146/2015, nota-se que se por um lado, nos diversos níveis, em especial, há para as crianças com deficiência, altas habilidades e superdotação apoio especializado na sala de aula, por outro, no ensino superior, muitos estudantes com deficiência precisam de um apoio especializado para se manter na universidade.

$\mathrm{O}$ artigo "Trajetórias escolares de pessoas com deficiências na educação básica: qual lugar da educação especial?", de Douglas Christian e João Henrique, baseia-se nas políticas públicas de inclusão da pessoa com deficiência, bem como na legislação aprovada em 1999. Eles narram a história de vida de quatro estudantes com deficiência que cursaram o ensino superior. Em seus depoimentos, os estudantes apontam para as dificuldades de se manterem no ensino superior revelando que a universidade ainda é um espaço para poucos. Ou seja, que a política de inclusão escolar das pessoas com deficiência vigente no Brasil, ainda não é eficiente

Ao estudarem esses processos excludentes, Vanderlei Balbino e Renata Naves, apontam em seu artigo, “A implementação da lei de cotas nas universidades", que ainda há um baixo número de pessoas com deficiência, negros, indígenas e quilombolas acessando o ensino superior e que apesar da implementação da Lei de Cotas, ainda é baixo o número de pessoas matriculadas no ensino superior.

Atualmente a população brasileira é composta por 45 milhões de pessoas com deficiência (BRASIL 2015), no entanto, ainda é baixa a quantidade de pessoas com deficiência que adentra e permanece no ensino superior, pois ao longo de séculos nosso ensino esteve voltado à exclusão dos minorizados, assim, aprender a incluir representa um grande desafio.

De acordo com a Lei Brasileira de Inclusão (LBI) - Lei No 13.146 (BRASIL, 2015), é obrigação do poder público, Art. 28 assegurar, criar, desenvolver, implementar e incentivar adoção de práticas pedagógicas inclusivas por meio da formação inicial e continuada dos professores, bem como habilitar profissionais para a oferta do atendimento educacional especializado voltado às várias necessidades educativas especiais.

É obvio que nas últimas duas décadas vêm sendo considerável o crescimento da legislação em relação aos processos de inclusão. No entanto, essas políticas públicas implementadas neste período, não vem dando conta de elevar o número de indígenas, negros, quilombolas e pessoas com deficiência na educação superior. Em seus escritos, Costa e 
Naves, apontam que o público da educação especial acessa de forma gradativa o ensino superior, registrando uma quase total invisibilidade desses sujeitos nas universidades.

Considerando que o Brasil é um país de dimensão continental, cuja área equivale a 8.511.965 quilômetros quadrados, a distribuição dos estudantes com deficiência no ensino superior é muito díspar. Só para exemplificar, dados do Instituto Nacional de Estudos e Pesquisas Educacionais Anísio Teixeira (INEP, 2010), revela que 49\% dos estudantes com deficiência matriculados estão na região Sudeste; $24 \%$ no Sul e $14 \%$ no Centro-oeste. Os números são mais alarmantes, quando observamos as regiões Nordeste e Norte, respectivamente, que contam apenas com $9 \%$ e $4 \%$ dessas matrículas no ensino superior.

Em seu artigo intitulado "A implementação da lei de cotas”, Costa e Naves denunciam o baixo número de estudantes indígenas, quilombolas, negros e pessoas com deficiência frequentando o ensino superior. Isso ficou evidenciado nos dados do INEP em 2010, alertando para o baixo número desses sujeitos sociais nas universidades brasileiras espalhadas pelo país.

O censo do INEP, aponta que o número de estudantes com deficiência é maior nas instituições particulares. De acordo com Rocha e Miranda (2009), no ano de 2005, o número de matrículas nas instituições de ensino superior privadas, envolvendo estudantes com deficiência, era de $67 \%$ e $33 \%$ nas universidades públicas.

Os dados revelam que as políticas públicas inclusivas implementadas no Brasil, em especial nas universidades não estão dando conta de promover à inclusão das pessoas com deficiência, dada a baixa inserção desses sujeitos na educação superior pública. Esses dados também são revelados por Douglas Christian e João Henrique, ao acentuar que há um baixo número de pessoas com deficiência frequentando as universidades.

Talvez um dos maiores desafios que a escola atual enfrenta no ensino comum, são as barreiras físicas, comunicacionais, sistêmicas pedagógicas e atitudinais, até porque, em todos os níveis do sistema educacional, ainda deparamos com essas no processo de inclusão e permanência dos estudantes com deficiência. Soma-se a essas dificuldades de acesso a comunicação os parcos recursos tecnológicos disponíveis nos diversos níveis do ensino voltados à inclusão das pessoas com deficiência, transtornos globais do desenvolvimento, altas habilidades/superdotação.

Pensamos que a universidade, em especial, os cursos de formação docente, se encontram frente a vários desafios, a saber: propor a construção de currículos adaptados, que viabilize a inclusão e a permanência dos estudantes com deficiência em todos os níveis de ensino; garantir nos espaços escolares, atendimento educacional especializado (AEE) voltados 
às diferentes necessidades educativas especiais; valorizar as diferenças e eliminar a homogeneidade, presentes nos currículos fechados e inflexíveis as mudanças exigidas pela escolas que pretendem incluir a todos.

Refletimos que o problema crucial não está na legislação aprovada nas últimas três décadas. As dificuldades para implementar essa legislação está no descompromisso dos governantes, que além de não tornarem a lei exequível, extingue conselhos que representam as diversas categorias, como indígenas, quilombolas, negros e pessoas com deficiência, dificultando ainda mais a inclusão e permanência destes nas universidades.

Consideramos que as políticas públicas educacionais implementadas pelo sistema, educacional, não vem dando conta de promover à inclusão das pessoas com deficiência nos diversos espaços educativos. A formação docente, presente nas universidades brasileiras, encontra dificuldades para formar professores que deem conta dessa tarefa, assim se faz necessário discutir também as práticas pedagógicas voltadas aos alunos com deficiência.

Nesse sentido, o artigo "Consultoria colaborativa como estratégia de formação continuada para professores que atuam com estudantes com deficiência intelectual" escrito por Danúsia Lago e Dulcéria Tartuci, apresenta os resultados de uma pesquisa de pósdoutorado, cujo objetivo foi analisar a Consultoria Colaborativa como estratégia pedagógica para formação continuada de professores que atuam com estudantes com deficiência intelectual. Trata-se de um estudo de abordagem qualitativa pautado nos pressupostos da pesquisa colaborativa e da Teoria Histórico Cultural.

A pesquisa ocorreu na Universidade Federal de Goiás - UFG e em duas escolas da rede estadual de ensino. Nesse recorte, analisaram a formação docente baseada na colaboração. Os resultados apontaram que esse tipo de formação proporciona discussões com foco na escolarização, apresenta caminhos possíveis para uma prática docente que visa a potencialidade desses estudantes e pode se constituir como prática interessante para os cursos de formação continuada.

Paula Vaz e Ana Paula Martins, em "Monitorização com base no currículo na escola inclusiva: adequação técnica das provas maze na triagem do risco de dislexia", apresentam um modelo de triagem do progresso acadêmico dos alunos que não respondem positivamente ao ensino eficaz que é ministrado na sala de aula regular. De acordo com elas esse modelo permite a identificação de alunos considerados em risco, antes de as suas dificuldades se agravarem e de experimentarem o insucesso por um longo período de tempo. O estudo foi realizado com um grupo de 82 alunos do $3 .^{\circ}$ ano de escolaridade de um agrupamento de escolas do norte de Portugal. Os dados analisados com recurso à estatística 
descritiva, inferencial, correlacional e à análise ROC permitiu concluir que as provas de MBC-Maze revelam boas caraterísticas técnicas, validade, sensibilidade e especificidade, que tornam segura a sua utilização por parte dos professores na monitorização do progresso dos alunos na leitura.

Compreende-se a partir da leitura do artigo das colegas que as provas de MBC-Maze, representam uma prática de intervenção pedagógica significativa para se trabalhar as necessidades acadêmicas, comportamentais e sociais dos alunos antes que essas prejudiquem seu desempenho na escola.

Sebastián-Heredero e Alexandra Anacha, em "Educação inclusiva. a percepção docente sobre conceitos, políticas e práticas inclusivas. estudo de caso no brasil”, apresentam o resultado de um estudo de caso de cunho qualitativo, realizado com 51 professores de escolas públicas do Mato Grosso do Sul. O estudo teve como objetivo conhecer como tem sido o processo de inclusão nas salas de aula, a partir da voz dos professores, bem como conhecer os fundamentos para as práticas educativas inclusivas a partir das opiniões e sugestões destes.

Os autores concluem afirmando que é necessário seguir trabalhando para o conhecimento e desenvolvimento da educação inclusiva, pois ainda há aqueles que não acreditam ou tem reticências no que se refere à inclusão. Afirmam também, que muito ainda há o que ser feito em matéria de formação e realização de ações, que ajudem os professores a atuarem dentro nesse modelo de educação, pois embora os profissionais demonstrem conhecer o conceito de educação inclusiva e dificuldades de aprendizagem, os conhecimentos sobre práticas includentes ainda são escassos.

Para eles, a escola que verdadeiramente consegue incluir a todos, ainda está sendo construída e carece de muito esforço e trabalho em equipe, de toda a sociedade.

Concordando com Sebastián-Heredero e Anacha, nós, organizadores desse dossiê, em nome dos dezenove colegas, cujos textos compõem esse trabalho, finalizamos afirmando aos leitores que as escolas, assim como as universidades, possuem apenas uma função, que é gerar saber. Mas não é qualquer saber. É,

Um saber comprometido com a verdade porque ela é a base da construção do conhecimento. Um saber comprometido com a justiça porque ela é a base das relações humanas. Um saber comprometido com a beleza porque ela possibilita a expressão da emoção e do prazer [...]. Um saber comprometido com a igualdade porque ela é a base da estrutura social inerente à condição humana. Um saber comprometido com o verdadeiro, o justo, o igualitário e o belo; é, em verdade, um compromisso com a transformação da sociedade, pois esses não são valores predominantemente estabelecidos e praticados na 
organização da vida humana, apesar de lhes serem próprios e inerentes (BELLONI, 1992, p. 73).

Assim, concluímos, dizendo que estamos comprometido(a)s com a igualdade, a justiça e a beleza. Itens fundamentais para qualquer modelo de educação. E se esses estão presentes, ela é includente, nesses tempos e em quaisquer outros tempos.

\section{REFERÊNCIAS}

BELLONI, I. Função da universidade: notas para reflexão. In.: BRANDÃO, Zaia et. al. Universidade e Educação. Campinas, SP: Papirus: Cedes; São Paulo: Ande: Anped, 1992. (Coletânea C.B.E.)

BRASIL. Lei n. 13.146, de 6 de julho de 2015. Institui a Lei Brasileira de Inclusão das Pessoas com Deficiência (Estatuto da Pessoa com Deficiência). Diário Oficial da União, Brasília, DF, 7 jul 2015.

BRASIL. Lei n. 9.394, 20 de dezembro de 1996. Estabelece as diretrizes e bases da educação nacional. Diário Oficial da União, Brasília, DF, 23 dez. 1996. Disponível em: https://www2.camara.leg.br/legin/fed/lei/1996/lei-9394-20-dezembro-1996-362578publicacaooriginal-1-pl.html. Acesso em: 19 dez. 2019.

BRASIL. Declaração de Salamanca e linha de ação sobre necessidades educativas especiais. 2. ed. Brasília, DF: Corde, 1997.

FREIRE, P. Pedagogia da autonomia: saberes necessários à prática educativa. 5.ed. Rio de Janeiro: Paz e Terra, 1996.

INEP. Censo Escolar da Educação Superior 2010. Brasília, DF: Ministério da Educação/Instituto Nacional de Estudos e Pesquisas Educacionais Anísio Teixeira, 2010.

MINAYO, M.C.S. O conceito de metodologia de pesquisa. In: MINAYO, M.C.S. (org). Pesquisa social: teoria, método e criatividade. 15. ed. Petrópolis: Vozes, 2000.

MISES, Roger. A criança deficiente mental. Rio de Janeiro, Zahar, 1977.

ROCHA, T. B; MIRANDA, T. G. A inclusão de alunos com deficiência no ensino superior: uma análise de seu acesso e permanência. In: DÍAZ, F., et al., orgs. Educação inclusiva, deficiência e contexto social: questões contemporâneas [online]. Salvador: EDUFBA, 2009, p. 27-37.

THESING, M. L. C; COSTAS, F. A. T. A pesquisa em educação: aproximações iniciais. RIAEE - Revista Ibero-Americana de Estudos em Educação, v. 12, n. 3, p. 1839-1853, jul./set. 2017.

UNESCO. Declaração mundial sobre educação para todos e plano de ação para satisfazer as necessidades básicas de aprendizagem. Jomtien, Tailândia: UNESCO, 1990. 
UNESCO. Marco da educação 2030: Declaração de Incheon. Incheon, Coréia do Sul: UNESCO, 2015.

\section{Como referenciar este artigo}

ROCHA, Leonor Paniago; REIS, Marlene Barbosa de Freitas; COSTA, Vanderlei Balbino da. Educação especial e inclusão: diálogos sobre pesquisa, políticas e práticas. Revista IberoAmericana de Estudos em Educação, Araraquara, v. 15, n. esp. 1, p. 872-883, maio 2020. eISSN: 1982-5587. DOI: https://doi.org/10.21723/riaee.v15iesp.1.13501

Submetido em: 11/10/2019

Revisões requeridas: $20 / 11 / 2019$

Aprovado em: 28/12/2019

Publicado em: 30/04/2020 